\title{
Functionally-Enhanced Derivative Spectroscopy (FEDS): A methodological approach
}

\author{
Manuel Palencia ${ }^{1}$ \\ ${ }^{1}$ GI-CAT, Department of Chemistry, Universidad del Valle, Cali-Colombia
}

Corresponding Author: M. Palencia. E-mail: manuel.palencia@correounivalle.edu.co

\section{Graphical Abstract}

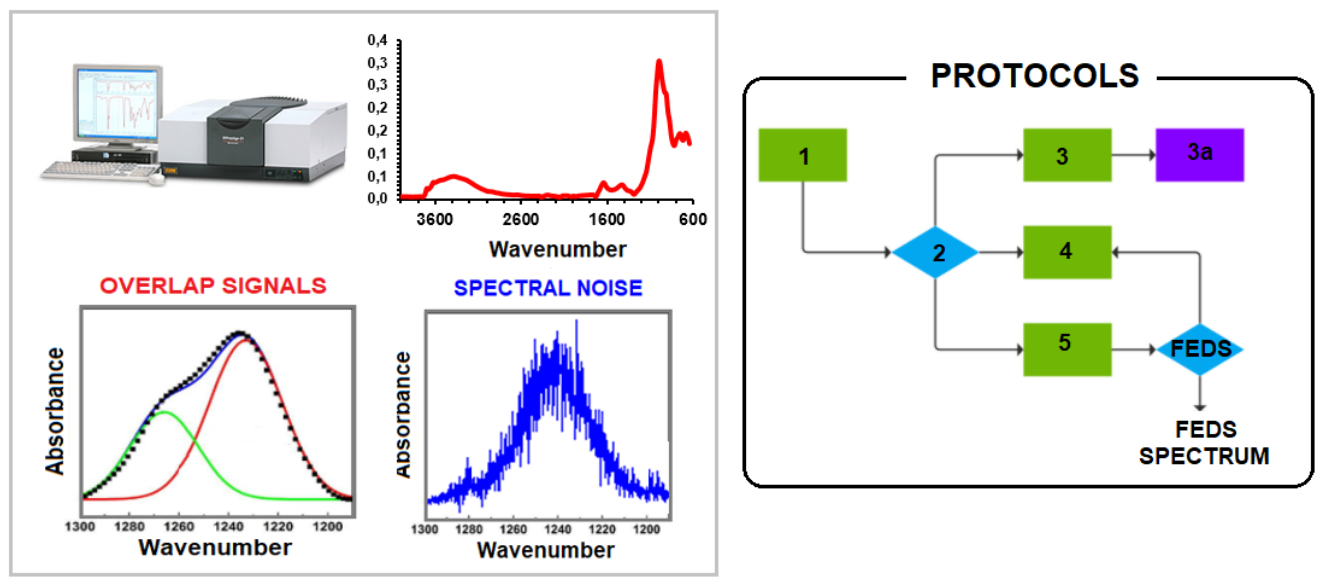

\begin{abstract}
Functionally-Enhanced Derivative Spectroscopy (FEDS) is a simple, fast and useful method which can be used to increase mathematically the spectral resolution of infrared spectra. Though is a developing analytical technique, at the present, several applications for its use in the analysis of infrared spectra have been described. However, it is use is limited because it is a new methodological propose which requires to advance in its evaluation and interpretation. By the above, a detailed description of procedure for its application is an important alternative to increase its use. The objective of this work is to describe the methodological steps for the use of FEDS.
\end{abstract}

Keywords: Vibrational spectrum, mid-IR spectrum, deconvolution, derivative spectroscopy, spectral analysis

H:

Cite as: Palencia M. Functionally-Enhanced Derivative Spectroscopy (FEDS): A methodological approach. J. Sci. Technol. Appl. 9 (2020) 29-34. https://doi.org/10.34294/j.jsta.20.9.63

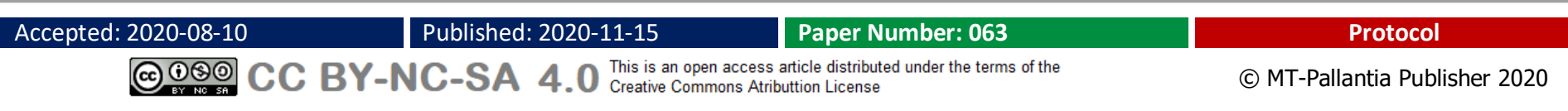




\section{Introduction}

Mid-infrared spectroscopy (Mid-IR Spectroscopy) is a well-known spectroscopic technique, based on the use of infrared radiation to produce changes of vibrational states at molecular level. In addition, it is a non-destructive, fast, easy to use and highly sensitive analytical methodology characterized because to require a small sample size without complex pre-treatment procedures. Mid-IR Spectroscopy is a very useful method for the determination of the presence or absence of functional groups, the analysis of molecular interactions, the monitoring and examination of changes in the intensity of signals (Alvarez-Ordoñez et al., 2011; Ojeda and Dittrich, 2012; Prakash et al., 2013). However, for the analysis of complex systems, the main limitations of infrared spectroscopy are the obtaining of very similar spectra in very different samples but with similar components, a high overlap of signals, and the widening of adjacent signals in multicomponent systems (AlvarezOrdoñez et al., 2011; Ojeda and Dittrich, 2012; Prakash et al., 2013). For the decrease of negative impact of these limitations, usually mathematical and computerized methods are used, being the most common the Fourier deconvolution (Friesen and Michaelian, 1991; Vazhnova et al., 2013; Palencia, 2018). However, though from a conceptual approach the Fourier deconvolution is simple, its application is limited by the 'complexity of computation', the appearing of negative intensities from calculations, the highly sensitive to the noise and the appearing of 'false' signals resulting of mathematical arguments without physical meaning (Friesen and Michaelian, 1991). In contrast, Functionally-Enhanced Derivative Spectroscopy (FEDS) is seen to be a simpler method for the deconvolution and the increase of spectral resolution of infrared signals (Palencia, 2018). Although FEDS was thought for the analysis of multicomponent systems, one-component systems also can be analyzed using the same procedures, and given that spectra for these systems can be defined as a combination of multiple vibrational patters resulting of different energetic states, the use of analysis FEDS for one-component system maintains the same objective than that for multi-component systems. A summarize of applications of FEDS are described in the Table 1.

The objective of this work is to describe the methodological steps for the use of FEDS by the analysis of ethanol as model of onecomponent system.

\section{Protocol: mIR-FEDS 2020}

Protocol described here, mIR-FEDS 2020, it contains small changes respect to procedure described in the initial publication of 2018 . These are the result of review and adaptation of FEDS algorithm during the analysis of a higher sample number and types. The FEDS application is based on four stage: recording of spectra, smoothing, auto-scaling, deconvolution by algorithm FEDS and analysis.

\subsection{Smoothing of spectra}

The aim of this procedure is to decrease the spectral noise and variability of data. Two key steps are included:
Table 1. Summarize of applications of FEDS 2018-2020.

\begin{tabular}{|c|c|c|}
\hline System & Objective & Reference \\
\hline Pure liquids & $\begin{array}{l}\text { Spectral characterization of water, } \\
\text { ethanol, butanol, hexanol, formic } \\
\text { acid, acetic acid, citric acid }\end{array}$ & (Palencia, 2018) \\
\hline $\begin{array}{l}\text { Binary liquid } \\
\text { mixture }\end{array}$ & $\begin{array}{l}\text { Deconvolution for the determination } \\
\text { of dimerization constant of acetic } \\
\text { acid in water }\end{array}$ & (Palencia, 2018) \\
\hline $\begin{array}{l}\text { Humified } \\
\text { organic matter }\end{array}$ & $\begin{array}{l}\text { Spectral characterization of humin } \\
\text { from agricultural soils }\end{array}$ & $\begin{array}{l}\text { (García-Quintero et } \\
\text { al., 2018) }\end{array}$ \\
\hline $\begin{array}{l}\text { Microbiological } \\
\text { surface }\end{array}$ & $\begin{array}{l}\text { Characterization of artificial biofilms } \\
\text { of nitrogen-fixing bacteria } \\
\text { (Azotobacter chroococcum) }\end{array}$ & (Berrio et al., 2018) \\
\hline Nanomaterials & $\begin{array}{l}\text { Deconvolution of surface plasmon } \\
\text { resonance in ultraviolet } \\
\text { spectroscopy of silver } \\
\text { nanoparticles }\end{array}$ & $\begin{array}{l}\text { (Sanchez et al., } \\
\text { 2018) }\end{array}$ \\
\hline Biosurfaces & $\begin{array}{l}\text { Mid-infrared spectral } \\
\text { characterization of fish scales from } \\
\text { "Bocachico" (Prochilodus } \\
\text { magdalenae) }\end{array}$ & $\begin{array}{l}\text { (Anaya-Tatis et al., } \\
\text { 2019) }\end{array}$ \\
\hline $\begin{array}{l}\text { Polymer } \\
\text { surface }\end{array}$ & $\begin{array}{l}\text { Deconvolution of mid-IR spectra of } \\
\text { PVC surface for biomedical } \\
\text { materials }\end{array}$ & $\begin{array}{l}\text { (Palencia et al., } \\
\text { 2019a) }\end{array}$ \\
\hline $\begin{array}{l}\text { Multicomponent } \\
\text { liquid systems }\end{array}$ & $\begin{array}{l}\text { Detection of solutes in the phase of } \\
\text { bulk liquid membranes }\end{array}$ & $\begin{array}{l}\text { (Palencia et al., } \\
\text { 2019b) }\end{array}$ \\
\hline $\begin{array}{l}\text { Binary liquid } \\
\text { mixture }\end{array}$ & $\begin{array}{l}\text { Deconvolution of mid-IR spectrum } \\
\text { of triethylamine-acetone }\end{array}$ & $\begin{array}{l}\text { (Otálora and } \\
\text { Palencia, 2019) }\end{array}$ \\
\hline $\begin{array}{l}\text { Polymer } \\
\text { hydrogels }\end{array}$ & $\begin{array}{l}\text { Deconvolution of mid-IR spectra of } \\
\text { polymer hydrogels }\end{array}$ & $\begin{array}{l}\text { (Otálora et al., } \\
\text { 2019) }\end{array}$ \\
\hline Polymer fibers & $\begin{array}{l}\text { Deconvolution of mid-IR spectra of } \\
\text { surface of cellulose fibers modified } \\
\text { with pyrolitic bio-oil }\end{array}$ & $\begin{array}{l}\text { (Palencia et al., } \\
\text { 2020b) }\end{array}$ \\
\hline $\begin{array}{l}\text { Polymer } \\
\text { matrixes }\end{array}$ & $\begin{array}{l}\text { Deconvolution of mid-IR spectra of } \\
\text { functional polyurethanes based on } \\
\text { cationic aminoglycosides and } \\
\text { loaded with phytohormones }\end{array}$ & $\begin{array}{l}\text { (Palencia et al., } \\
\text { 2020a) }\end{array}$ \\
\hline $\begin{array}{l}\text { Polymer } \\
\text { matrixes }\end{array}$ & $\begin{array}{l}\text { Antibacterial and non-hemolytic } \\
\text { cationic polyurethanes with } \mathrm{N} \text { - } \\
\text { carboxymethyl-N,N,N-} \\
\text { triethylammonium groups }\end{array}$ & $\begin{array}{l}\text { (Palencia et al., } \\
\text { 2020d) }\end{array}$ \\
\hline $\begin{array}{l}\text { Microbiological } \\
\text { surface }\end{array}$ & $\begin{array}{l}\text { Characterization of outer surface of } \\
\text { Helicobacter pylori biofilms }\end{array}$ & $\begin{array}{l}\text { (Palencia et al., } \\
\text { 2020c) }\end{array}$ \\
\hline
\end{tabular}

- Ensuring reproducibility: For a sample, spectra must be recorded at least in triplicate, using the same experimental parameters. This is suggested in order to decrease the noise and the random effects by the use of averaged spectrum. In addition, spectra are usually recorded in absorbance or transmittance units, they should not be modified by the equipment software, and some type of baseline correction should not be applied. The above is in order to advance in the building of comparable FEDS spectra, therefore, all information related with number of replicates, resolution, among others should be reported.

- Decreasing the noise: Any smoothed algorithm can be used, however, it is suggested ABSF because is simple and easy to usage (Palencia et al., 2018). 
Table 2. Example of smoothing based on ABSF filter.

\begin{tabular}{|c|c|c|c|c|}
\hline \multirow[t]{2}{*}{$j$} & \multicolumn{2}{|c|}{ Averaged data } & \multicolumn{2}{|c|}{ Smoothed data } \\
\hline & $v_{j}\left(\mathrm{~cm}^{-1}\right)$ & $a_{j}$ (u.a.) & $w_{j}\left(\mathrm{~cm}^{-1}\right)$ & $b_{j}$ (u.a.) \\
\hline 1 & 501.0 & 0.824 & $w_{1}=\frac{a_{1}+a_{2}+a_{3}}{3}=501.0$ & $b_{1}=\frac{a_{1}+a_{2}+a_{3}}{3}=0.827$ \\
\hline 2 & 502.0 & 0.827 & $w_{1}=\frac{a_{2}+a_{3}+a_{4}}{3}=502.0$ & $b_{1}=\frac{a_{1}+a_{2}+a_{3}}{3}=0.823$ \\
\hline 3 & 503.0 & 0.831 & $w_{1}=\frac{a_{3}+a_{4}+a_{5}}{3}=503.0$ & $b_{1}=\frac{a_{1}+a_{2}+a_{3}}{3}=0.817$ \\
\hline 4 & 504.0 & 0.812 & 504.0 & 0.813 \\
\hline 5 & 505.0 & 0.808 & 504.5 & 0.814 \\
\hline 6 & 506.0 & 0.820 & 505.0 & 0.820 \\
\hline
\end{tabular}

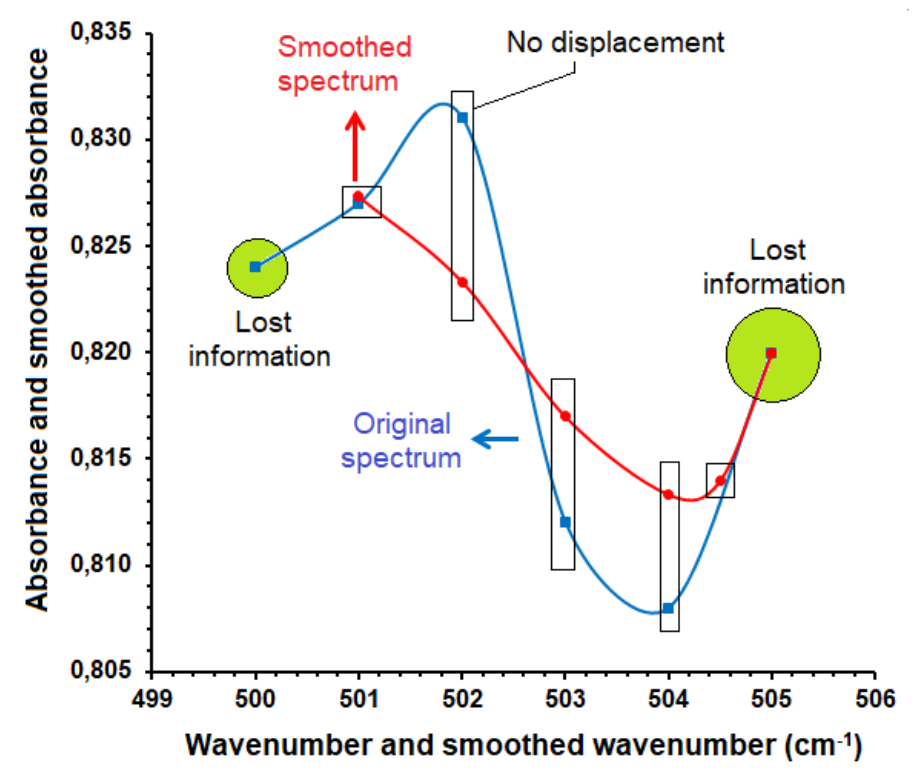

Figure 1. Illustration of smoothing based on ABSF filter for data in Table 1 (Number of cycles $=1$ ).

$$
\operatorname{ABSF}\left(a_{i} ; N=20\right)=\left.\frac{1}{3} \sum_{j}^{j+2}\left(a_{j}\right)\right|_{N=1} ^{N=20}
$$

where $a_{j}$ is the $j$-th absorbance. ABSF is the moving average with a data window of 3 and 20 cycles $(N=20)$. Thus, for each $a_{j}, a_{j+1}$ and $a_{j+2}$, the corresponding average value is calculated, and subsequently, this procedure is repeated $N$ times. In addition, the same transformation of data must be performed on values of wavenumbers $(v)$ to correct the displacements respect to original spectrum (i.e., maximum points in original spectrum should be the same in the original and smoothed spectra) (Palencia, 2018). Here, it is recommended the use of $N=20$, but depending of quality of spectra in term of noise, values of $N$ larger than 20 could be used. Thus, for the first cycle, new spectral data are calculated by

$$
b_{j}=\frac{a_{j}+a_{j+1}+a_{j+2}}{3}
$$

Note that equation 2 is only a different form to write the equation 1 . It is important to note that, as result of smoothing using the equation 1 , a number of data equal to two times the number of applied cycles is lost (i.e., if analysis window is $500 \mathrm{~cm}^{-1}$ to $4000 \mathrm{~cm}^{-1}$ then the new range obtained will be $520 \mathrm{~cm}^{-1}$ to $3980 \mathrm{~cm}^{-1}$ ). Smoothing by ABSF filter is exemplified step-by-step in Table 2. Corresponding illustration is shown in Figure 1.

\subsection{Auto-scaling of spectra}

The goal of this procedure is to delimit the absorbance data between zero and one. For that

$$
q_{j}=\frac{b_{j}-b_{\min }}{b_{\max }-b_{\min }}
$$

where $q_{j}$ is the corresponding auto-scaled absorbance. In order to avoid calculation mistakes resulting to scaling from 0 to 1 during the application of FEDS algorithm, the zero absorbance, $q_{j}=0$, must be approximated by the calculation of average value between two adjacent values of absorbance satisfying: $q_{j-1}<q_{j}<q_{j+1}$ when $q_{j}=0$. Note that any other procedure could be performed in order to eliminate $b_{j}=0$. Here, it is recommended the calculation of the average between adjacent values because it is easy to automatize even in a spreadsheet and, being the lowest absorbance value, the effect on the spectrum is negligible.

Note that FEDS can be applied to the entire spectrum or to a portion of it. It is desirable to perform FEDS at intervals and not the full spectrum, since a signal with a relatively high intensity can cause a strong decrease in the intensity of the adjacent data. A narrow interval provided greater ease of analysis, an aspect of great importance considering that the complexity of the FEDS spectrum is greater than that of the original spectrum. An illustration using the same data in Table 1 is shown in the Table 2.

\subsection{Transformation of data by FEDS}

For the obtaining of FEDS intensities, the first step is the calculation of the first-order derivative of the inverse of normalized spectrum, later, it is calculated the square root of the absolute value of the previous result, and subsequently, it is calculated the respective inverse. A factor $1+q_{j}$ is introduced in order to assign a weight to the intensities from the experimental data. Finally, FEDS data are 
normalized respect to the maximum value. The above can be described in one single steps, but, in order to be didactic, three steps are shown below:

$$
\begin{gathered}
x_{j}=\left|\frac{1}{q_{j}}-\frac{1}{q_{j-1}}\right| \\
y_{j}=\frac{1+q_{j}}{\sqrt{x_{j}}} \\
p_{j}=\frac{y_{j}}{y_{\max }}
\end{gathered}
$$

where $x_{j}$ and $y_{j}$ are auxiliary functions, $p_{j}$ is the normalized result of called "function P", and $y_{\max }$ is the maximum value of auxiliary function $y$. Note that, all data are transformed without alteration in their relative position, and with adequate scale factor $(\phi)$ is possible to increase or decrease the FEDS intensities. In particular, if $\phi<1$, then intensities are increased. Thus,

$$
p_{j}=\frac{y_{j}}{\phi y_{\max }}
$$

\subsection{Analysis of FEDS spectrum}

To carry out the analysis of FEDS spectra is possible to define several strategies. Really, analysis depend on each researcher. However, to be ease the analysis, here it is shown a systematic procedure. Besides, a standard terminology is introduced and recommended.

Always that FEDS analysis is applied, after to obtain the corresponding FEDS spectrum (here, by spectrum should be understood the total spectrum or any range of interest). In addition, it is recommended to carry out its overlapping with the experimental spectrum, thus, it is possible identify the main signals of IR spectrum transferred to FEDS spectrum. Note that, it is expected that all signals in the IR spectrum appear in the FEDS spectrum, this signal are named as "inherited signals". The above sometimes is not true because the relative intensity with respect to the normalization signal, the overlapping of signals, and the width of the adjacent signals influences the transfer of the signals from the IR spectrum to the FEDS spectrum. However, the overlapping of spectra permits identify the inherited signals which have the same physical meaning assigned in the infrared spectroscopy. Therefore, the overlapping of the spectra eases the assignation of signals since the problem is reduced to classical analysis used in IR spectroscopy.

On the other hand, other signals are "pure signals", it is to say, signals resulting of FEDS and not necessarily they are associated with signals of IR spectrum. Two types of pure signals can be identified: "Hidden signals", and "Gauss-overlay signal". In the first case, Hidden signals are signals that were hidden and that by action of the algorithm are showed in the FEDS spectrum, these signals have a physical meaning equal to the respective signals in the IR spectrum, however, they are not clearly visible and, in consequence, their assignation should be performed very carefully, using comparisons with IR spectra of the compounds or substances that are most similar to the samples, or by comparing with simulated spectra using some computational method well-stablished. Gaussoverlay signals are signals caused by the effect of adjacent bands. They are not yet fully understood and their study is currently in development. However, it is known that when two adjacent Gaussian signals overlap, depending on the distance and degree of overlap, a third signal associated with such overlap emerges. This signal impact the shape of FEDS spectrum, but has the advantage that they are relatively easy to identify, usually, they are associated with a relative minimum. These signals have been used to measure displacements and to validate the existence of two overlapping signals (Palencia et al., 2020; Palencia et al., 2021). In Figure 2 is exemplified FEDS deconvolution for mid-IR of soil sample obtained by attenuated total reflectance (ATR).

\section{Conclusions}

A systematic description of protocol for the application of FEDS was described. It can be concluded that FEDS is an easy tool for the mid-IR analysis of complex samples where overlap makes analysis difficult. In addition, an important factor determining the quality of analysis is the reproducibility, in consequence, at least three spectra should be recording for each sample. Finally, three types of FEDS signals can be identified throughout the spectrum: (i) Inherited signals, (ii) Hidden signals, and (iii) Gauss-overlay signals. It is

\begin{tabular}{|c|c|c|c|c|c|}
\hline \multicolumn{2}{|c|}{ Smoothed data } & \multicolumn{2}{|c|}{ Normalized data } & \multirow{2}{*}{$\begin{array}{c}\text { Change } \\
\text { of } \\
q=0\end{array}$} & \multirow[b]{2}{*}{ Observations } \\
\hline $\begin{array}{c}w_{j} \\
\left(\mathrm{~cm}^{-1}\right)\end{array}$ & $\begin{array}{c}\boldsymbol{b}_{j} \\
\text { (u.a.) }\end{array}$ & $\begin{array}{c}w_{j} \\
\left(\mathrm{~cm}^{-1}\right)\end{array}$ & $q_{j}$ & & \\
\hline 502.0 & 0.823 & 502.0 & 1.000 & 1.000 & $q_{\max }$ \\
\hline 503.0 & 0.817 & 503.0 & 0.367 & 0.367 & - \\
\hline 504.0 & 0.813 & 504.0 & 0.000 & 0.217 & $q_{\min }=(0.367+0.067) / 2$ \\
\hline 504.5 & 0.84 & 504.5 & 0.067 & 0.067 & - \\
\hline
\end{tabular}
necessary advance in the standardization of signals for an adequate implementation of the tool in short time.

Table 2. Example of normalization using the equation $5\left(q_{\max }=1\right.$ and $\left.q_{\min }=0\right)$.

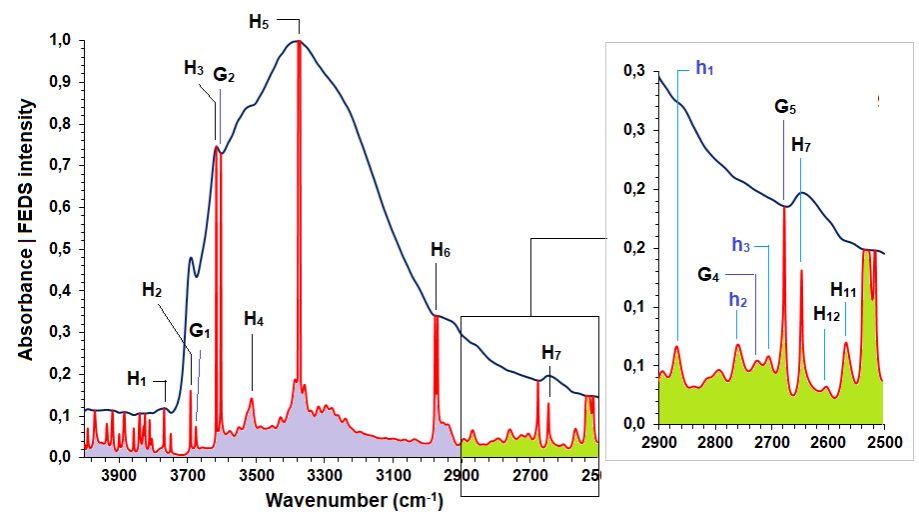

Figure 2. Example of FEDS spectrum (red line) obtained by deconvolution of midIR spectrum (blue line) of one soil sample: $\mathbf{H}$ denotes "Inherited signals", $\mathbf{h}$ denotes "Hidden signals" and G denotes Gauss-overlay signals. 
米

Conflict interest. Authors declare that there is no conflict of interest regarding the publication of this paper.

Acknowledgements. M. Palencia thanks to University del Valle and Mindtech s.a.s. (AFICAT MT-UV 2018-2023).

\section{References}

Alvarez-Ordoñez A., Mouwen D., Lopez M., Prieto M. (2011) Fourier transform infrared spectroscopy as a tool to characterize molecular composition and stress response in foodborne pathogenic bacteria. Journal of Microbiological Methods 84:369-378. https://doi.org/10.1016/j.mimet.2011.01.009

Anaya-Tatis L., Libreros K.H., Palencia V.J., Atencia V.J., Palencia M. (2019) Mid-infrared spectral characterization of fish scales: "Bocachico" (Prochilodus magdalenae) by functionally-enhanced derivative spectroscopy (FEDS) - A methodological approach. Journal of Science with Technological Applications 6:28-39. https://doi.org/10.34294/j.jsta.19.6.39

Berrio M.E., Palencia S.L., Lerma T.A., Mora M.A. (2018) Bacterial colonization modelling on soil particles: Effect of humic acids on the formation of nitrogen-fixing bacteria biofilms. Journal of Science with Technological Applications 5:33-44. https://doi.org/10.34294/j.jsta.18.5.33

Friesen W., Michaelian K. (1991) Deconvolution and Curve-Fitting in the Analysis of Complex Spectra: The CH Stretching Region in Infrared Spectra of Coal. Applied Spectroscopy 45:50-56. https://doi.org/10.1366/0003702914337812

García-Quintero M., Combatt E., Palencia M. Structural study of humin and its interaction with humic acids by Fourier-transform midinfrared spectroscopy. Journal of Science with Technological Applications 4 (2018) 28-39. https://doi.org/10.34294/j.jsta.18.4.28

Ojeda J., Dittrich M. (2012) Fourier transform infrared spectroscopy for molecular analysis of microbial cells. Chapter 8. In Navid A. Microbial systems biology: Methods and Protocols, Methods in Molecular Biology. Springer Science. https://doi.org/10.1007/978-1$\underline{61779-827-6 \_8}$

Otálora A., Palencia M. (2019) Application of functionally-enhanced derivative spectroscopy (FEDS) to the problem of the overlap of spectral signals in binary mixtures: triethylamine-acetone. Journal of Science with Technological Applications 6:96-107. https://doi.org/10.34294/j.jsta.19.6.44

Otálora A., Lerma T.A., Palencia M. (2019) Synthesis and characterization of polurea-based Hydrogels by Multicomponent Polycondensation of 1,6-Hexamethylenediisocyanate, sorbitol and cysteine. Journal of Science with Technological Applications 7:516. https://doi.org/10.34294/j.jsta.19.7.47

Palencia M. (2018) Functional transformation of Fourier-transform mid-infrared spectrum for improving spectral specificity by simple algorithm based on wavelet-like functions. Journal of Advanced Research 14:53-62. https://doi.org/10.1016/j.jare.2018.05.009

Palencia M, Lerma T., Afanasjeva N. (2019a) Antibacterial cationic poly(vinyl chloride) as an approach for in situ pathogen-inactivation by surface contact with biomedical materials. European Polymer Journal 115:212-220. https://doi.org/10.1016/j.eurpolymj.2019.03.041

Palencia M., Lerma T.A., Arrieta A.A. (2020) Antibacterial and non-hemolytic cationic polyurethanes with N-carboxymethyl-N,N,Ntriethylammonium groups for bacteremia-control in biomedical-using materials. Materials Today Communications 22:100708. https://doi.org/10.1016/j.mtcomm.2019.100708

Palencia M., Lerma T.A., Cordoba A. (2016) Polyurethanes with boron retention properties for the development of agricultural fertilization smart systems. Journal of Science with Technological Applications 1:39-52. https://doi.org/10.34294/j.jsta.16.1.4

Palencia M., Mora M., Lerma T. (2019b) Study of time-dependent diffusion coefficient into liquid membrane systems and its application to polyphenol extractions from sugarcane bagasse. Journal of Science with Technological Applications 6:40-52. https://doi.org/10.34294/j.jsta.19.6.40 
Palencia M., Mora M., Lerma T.A. (2020a) Environment-friendly stimulus sensitive polyurethanes based on cationic aminoglycosides for the controlled release of phytohormones. Smart and Sustainable Built Enviroment. https://doi.org/10.1108/SASBE-09-2019-0126

Palencia M., Mora M.A., Lerma T.A., Afanasjeva N., Isaza J.H. (2020b) Reinforcing agents based on cellulose fibers modified by insertion of end-alkyl groups obtained from pyrolytic bio-oil of sugarcane bagasse. Polymer Bulletin 77:5711-5724. https://doi.org/10.1007/s00289-019-03050-0

Palencia S.L., García A., Palencia M. (2020c) Vibrational Spectrum characterization of outer surface of Helicobacter pylori biofilms by functionally-enhanced derivative spectroscopy (FEDS). Journal of Chilean Chemical Society 65:5016-5022. http://dx.doi.org/10.4067/S0717-97072020000405015

Palencia S.L., García A., Palencia M. (2021) Mid-infrared vibrational spectrum characterization of the outer surface of Candida albicans by functionally enhanced derivative spectroscopy (FEDS). Applied Spectroscopy. (Accepted)

Prakash J., Kar S., Lin C., Chen C.Y., Chang C.F., Jean J.S., Kulp T.R. (2013) Identification and discrimination of bacteria using Fourier transform infrared spectroscopy. Spectrochimica Acta Part A: Molecular and Biomolecular spectroscopy 116:478-484. https://doi.org/10.1016/j.saa.2013.07.062

Sanchez Y., García-Quintero A., Palencia M. Determination and distribution of size of inorganic particles by spectral deconvolution of surface plasmon resonance. Journal of Science with Technological Applications 5 (2018) 45-54. https://doi.org/10.34294/j.jsta.18.5.34

Vazhnova T., Lukyanov D. (2013) Fourier Self-Deconvolution of the IR Spectra as a Tool for Investigation of Distinct Functional Groups in Porous Materials: Brønsted Acid Sites in Zeolites. Anal Chem 85:11291-11296. https://doi.org/10.1021/ac4020337

米

(C) MT-Pallantia Publisher (2020) 